\title{
A PROSPECTIVE STUDY COMPARING GLASGOW SCALE WITH CT SEVERITY INDEX IN RELATION TO SEVERITY OF ACUTE PANCREATITIS
}

\section{General Surgery}

\section{Swapnil Sen*}

\begin{tabular}{l} 
Subir Kumar \\
Kanjilal \\
\hline Dipak \\
Chakraborty
\end{tabular}

MBBS, DNB (General Surgery), FIAGES, Resident Surgeon, Department of General Surgery, Vivekananda Institute of Medical Sciences, West Bengal University of Health Sciences, Kolkata. *Corresponding Author MBBS, MS (General Surgery), MCh (Urology), Additional Chief Health Director, B.R. Singh Hospital and Centre for Medical Education \& Research, Sealdah, Kolkata.

MBBS, MS (General Surgery), Visiting Consultant, Department of General Surgery, B.R. Singh Hospital and Centre for Medical Education \& Research, Sealdah, Kolkata.

\begin{abstract}
Acute pancreatitis includes a wide spectrum of disease which can range from mild self-limiting symptoms to a fulminant process and may result in multiple organ failure and high mortality. No highly sensitive and specific test or severity scoring system exists that can accurately measure prognosis at admission and a lack of consensus still prevails as to which severity scoring system is the best predictor of prognosis and final outcome in a case of acute pancreatitis.

Aim: To study the efficacy of prediction of severity of Acute Pancreatitis using Glasgow Prognostic Scale and CT Severity Index and to determine whether Glasgow Prognostic Scale and CT Severity Index correlate in predicting the severity of Acute Pancreatitis.

Materials And Methods: Hospital based prospective observational study on 102 patients admitted in General Surgical wards with features of Acute Pancreatitis at a tertiary care centre of Eastern India. Categorical variables are expressed as Number and percentage of patients and compared across the groups using Pearson's Chi Square test for Independence of Attributes. The statistical software SPSS version 20 has been used for the analysis. An alpha level of $5 \%$ has been taken, i.e. if any p value is less than 0.05 , it has been considered as significant.

Results: 1 . The correlation between Glasgow Prognostic score and the Ranson's score was found to be statistically significant.

2. The correlation between CT severity index score and Ranson's score was found to be statistically significant.

3. The sensitivity and specificity of the CT Severity Index was found to be $81.48 \%$ and $61.33 \%$ respectively. The positive and negative predictive values were found to be $43.14 \%$ and $90.20 \%$ respectively. The diagnostic accuracy was $66.67 \%$.

The sensitivity and specificity of the Glasgow Prognostic Score was found to be $74.07 \%$ and $62.67 \%$ respectively. The positive and negative predictive values were found to be $41.67 \%$ and $87.04 \%$ respectively. The diagnostic accuracy was $65.69 \%$.

Conclusion:Ranson's Prognostic Score, Glasgow Prognostic Score and the CT Severity Index correlate with each other in cases of Acute
\end{abstract} Pancreatitis.

\section{KEYWORDS}

Acute pancreatitis; Prognostic Scoring Systems, Ranson's Prognostic Score, Glasgow Prognostic Score, CT Severity Index Score

\section{INTRODUCTION:}

Acute pancreatitis includes a wide spectrum of disease which can range from mild self-limiting symptoms to a fulminant process and may result in multiple organ failure and high mortality.

Acute pancreatitis is defined as an acute condition which presents with abdominal pain and is usually associated with raised pancreatic enzyme levels in the blood or urine due to pancreatic inflammation. Recurrence may be seen in acute pancreatitis. ${ }^{2}$

Most patients suffering from acute pancreatitis experience relatively minor episodes of disease characterised by mild parenchymal edema without distant organ dysfunction and an uneventful recovery. Severe episodes can progress to extensive pancreatic necrosis, development of Systemic Inflammatory Response Syndrome, multiorgan failure, rapid clinical deterioration and even death.,

Multi-factorial scoring systems, including Ranson et $\mathrm{al}^{6}$ and Acute Physiology and Chronic Health Evaluation (APACHE)-II scores ${ }^{7}$ have been used since the 1970s for assessment of the severity of AP. Balthazar computed tomography severity index (CTSI) ${ }^{8}$ was developed in 1990. These predictive methods have been established as an important tool for assessment of the severity ofAP.

A variety of predictive systems have been developed with the goal of assisting clinicians in predicting prognosis. However, no highly sensitive and specific test or severity scoring system exists that can accurately measure prognosis at admission and a lack of consensus still prevails as to which severity scoring system is the best predictor of prognosis and final outcome in a case of acute pancreatitis.

\section{AIMS AND OBJECTIVES:}

1. To study the efficacy of prediction of severity of Acute Pancreatitis using Glasgow Prognostic Scale and CT Severity Index and to determine whether Glasgow Prognostic Scale and CT Severity Index correlate in predicting the severity of Acute Pancreatitis.
2. To streamline management and limit morbidity associated with severe Acute Pancreatitis by early detection and severity assessment.

3. To assess and compare the results of Glasgow Prognostic Scale and CT Severity Index in comparison with Ranson's Prognostic Scale in patients with Acute Pancreatitis with respect to Sensitivity, Specificity, Positive Predictive value, Negative Predictive value and Diagnostic accuracy

\section{MATERIALSAND METHODS:}

\section{Study Site:}

Patients admitted in General Surgical wards for evaluation of Acute Pancreatitis at B.R. Singh Hospital and Centre for Medical Education and Research, Eastern Railway, Sealdah, Kolkata -14

Design of Study: Prospective Observational Study.

Sample size: 102

Study Duration: The study was done from 1 st November 2015 to $31^{s}$ October 2016.

\section{Inclusion Criteria:}

a) Age $>18$ years

b) Patients with clinically evident features of Acute Pancreatitis like

* Epigastric and or periumbilical pain that radiates to the back.

* Nausea and or vomiting that does typically does not relieve the pain

* Dehydration, poor skin turgor, tachycardia, hypotension and dry mucous membranes.

* Rarely, patients may present with flank and periumbilical ecchymosis.

Exclusion Criteria:

a) Patients with recurrent pancreatitis

b) Patients who are diagnosed cases of other causes of acute abdomen

like acute intestinal obstruction, peptic ulcer perforation, etc.

c) Patient's refusal to be a part of the study. 
STATISTICALANALYSIS USED:

Sample Size Calculation:

Suppose P1 and P2 denote the expected Sensitivity of two alternative diagnostic tests respectively. the required sample size with $1-\alpha$ confidence level and $1-\beta$ power is

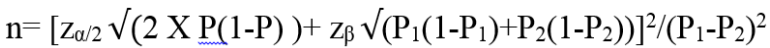

Where $\mathrm{P}$ is the average of $\mathrm{P}_{1}$ and $\mathrm{P}_{2}$ and $\mathrm{Z}_{\alpha}, \mathrm{Z}_{\beta}$ are the standard normal $\mathrm{Z}$ values corresponding to $\alpha$ and $\beta$ (the probability of type I and type II errors respectively).

Here $\alpha=5 \%$, hence $\mathrm{Z}_{\alpha / 2}=1.96$ and power is $80 \%$ and hence $\mathrm{Z}_{1-\beta}$ is 0.84 . $\mathrm{P} 1=0.9, \mathrm{P} 2=0.75$. Taking these values and applying the above formula we get the sample size to be 100

\section{Statistical Methods:}

Categorical variables are expressed as Number of patients and percentage of patients and compared across the groups using Pearson's Chi Square test for Independence of Attributes.

Continuous variables are expressed as Descriptive Statistics

Sensitivity, specificity, PPV, NPV and Diagnostic accuracy have been calculated to understand the association between the detection methods.

The statistical software SPSS version 20 has been used for the analysis.

An alpha level of $5 \%$ has been taken, i.e. if any p value is less than 0.05 it has been considered as significant.

\section{RESULTS:}

1. $26.5 \%$ patients had severe pancreatitis as determined by the Ranson's score.

2. $47 \%$ patients had severe disease as determined by the Glasgow Prognostic Index.

3. $33.3 \%$ cases had mild pancreatitis, $16.7 \%$ cases had moderate pancreatitis whereas severe pancreatitis was seen in $50 \%$ cases as evaluated by the CT Severity Index.

4. COMPARISON OF GLASGOW PROGNOSTIC SCORE WITH RANSON'S PROGNOSTIC SCORE:

If we divide all the cases into severe and non severe, among the 102 patients, 20 patients who had severe pancreatitis as determined by the Ranson's score also had severe disease as assessed by the Glasgow Prognostic score. The correlation was found to be statistically significant.

5. COMPARISON OF CT SEVERITY INDEX WITH RANSON'S PROGNOSTIC SCORE

Among the 102 patients, 22 patients who had mild pancreatitis as determined by the Ranson's score also had mild disease as assessed by the CT Severity Index score. Again, 22 patients had severe disease which correlated with both the Ranson's score as well as the CT Severity Index score. The correlation was found to be statistically significant.

6. DETERMINATION OF DIAGNOSTIC ACCURACY

The sensitivity and specificity of the CT Severity Index was found to be $81.48 \%$ and $61.33 \%$ respectively. The positive and negative predictive values were found to be $43.14 \%$ and $90.20 \%$ respectively. The diagnostic accuracy was $66.67 \%$.

The sensitivity and specificity of the Glasgow Prognostic Score was found to be $74.07 \%$ and $62.67 \%$ respectively. The positive and negative predictive values were found to be $41.67 \%$ and $87.04 \%$ respectively. The diagnostic accuracy was $65.69 \%$.

All the results were obtained taking the Ranson's Prognostic criteria as the yardstick for comparison.

\section{DISCUSSION:}

\section{PATHOPHYSIOLOGY OF ACUTE PANCREATITIS:}

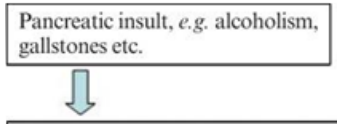

Premature activation of trypsinogen and other proteolytic enzymes

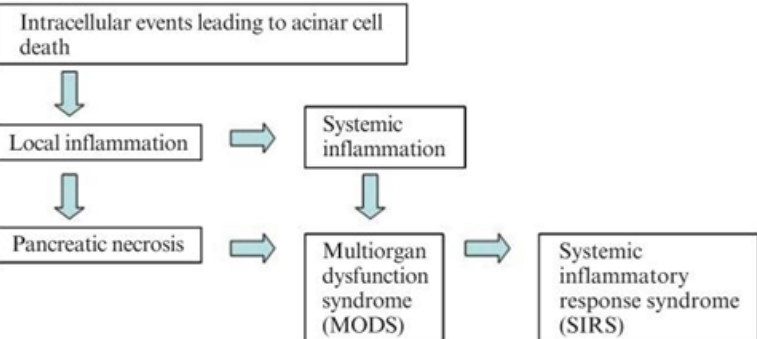

ASSESSMENT OF SEVERITY: 
0-3: Acute Pancreatitis mild

4-6: Acute Pancreatitis moderate

7-10: Acute Pancreatitis severe

For assessment of the severity of AP, the Ranson score represented a major advancement in evaluation of disease severity in AP and has been used clinically for more than three decades. ${ }^{6,13}$ In this study, The Ranson criteria has been considered as the yardstick with which other scoring systems like the Glasgow Prognostic Score and the CT Severity Index have been compared.

The CTSI was found to be useful in identification of patients with severe AP and predict poor prognosis in selected patients. Even if contrast-enhanced CT has been considered the gold standard for diagnosing pancreatic necrosis, early scanning for the prediction of severity is limited because the full extent of pancreatic necrosis may not develop within the first 48 hour of presentation. ${ }^{14}$

In this study, CT scan of the whole abdomen has been done 72 hours after admission. The variables of the Ranson and the Glasgow prognostic criteria were evaluated at admission and within 48 hours as per the criteria. In this study, when the values were compared keeping the Ranson's severity Index as the yardstick, then the sensitivity and specificity of the CT Severity Index were $81.48 \%$ and $61.33 \%$, respectively. In cases with acute pancreatitis, it was found that there was correlation between the results of Glasgow Prognostic score and CT Severity Index. It could also be inferred that the Glasgow Prognostic score may be used as an effective means to prognosticate the disease. Also, in this study, the correlation between Ranson's Prognostic criteria with CT Severity Index was found to be statistically significant

The advantage of the Glasgow multifactor scoring system is that nine factors are evaluable on admission and thus it may be simpler to apply than the Ranson's criteria. In this study, the sensitivity and specificity of the Glasgow Prognostic Score was found to be $74.07 \%$ and $62.67 \%$. From the results, it may be inferred that the laboratory and/or clinical symptoms and the CE-CT findings are independent risk factors. Severity scoring systems like Glasgow or Ranson's Prognostic score alone may diagnose severe Acute Pancreatitis or it can be diagnosed by the CECT findings alone. It is therefore, recommended to perform CECT examination in those patients who were diagnosed as moderate to severe acute pancreatitis by laboratory/clinical severity criteria.

There were some limitations in this study. In this study, the number of cases of severe AP was lower compared to other large scale clinical studies; therefore, comparison of prognostic value of various scoring systems was somewhat difficult. This study can be extended further with the addition of single biochemical markers which may have a significant role in severity assessment and prognostication of the disease.

\section{Tables:}

Table 1: Comparison Of Glasgow Prognostic Score With Ranson's Prognostic Score:

\begin{tabular}{|c|c|c|c|c|c|}
\hline \multirow[t]{2}{*}{$\begin{array}{l}\text { Scoring } \\
\text { system }\end{array}$} & \multicolumn{2}{|c|}{$\begin{array}{l}\text { SEVERE } \\
\text { DISEASE - } \\
\text { GLASGOW } \\
\text { SCORE }\end{array}$} & \multirow[t]{2}{*}{ Total } & \multirow[b]{2}{*}{ p Value } & \multirow[b]{2}{*}{$\begin{array}{c}\text { Significanc } \\
\text { e }\end{array}$} \\
\hline & $\mathrm{NO}$ & YES & & & \\
\hline \multirow{2}{*}{$\begin{array}{c}\text { Severe Disease } \\
\text { - RANSON } \\
\text { SCORE }\end{array}$} & $\mathrm{NO}$ & $47(87.04)$ & $28(58.33)$ & $\begin{array}{c}75 \\
(73.53)\end{array}$ & \multirow[t]{3}{*}{\begin{tabular}{|l|l|}
0.001 & Signi \\
& ficant
\end{tabular}} \\
\hline & YES & $7(12.96)$ & $20(41.67)$ & $\begin{array}{c}27 \\
(26.47)\end{array}$ & \\
\hline \multicolumn{2}{|l|}{ Total } & $54(100)$ & $48(100)$ & $\begin{array}{c}102 \\
(100)\end{array}$ & \\
\hline
\end{tabular}

Table 2: Comparison Of CT Severity Index With Ranson's Prognostic Score:

\begin{tabular}{|c|c|c|c|c|c|c|}
\hline \multirow[t]{2}{*}{ Scoring system } & \multicolumn{3}{|c|}{\begin{tabular}{|l|} 
Severe Disease - CT \\
Severity Index \\
Score
\end{tabular}} & \multirow[t]{2}{*}{$\begin{array}{l}\text { Tota } \\
\text { l }\end{array}$} & \multirow[b]{2}{*}{ p Value } & \\
\hline & $\begin{array}{l}\text { MIL } \\
\text { D }\end{array}$ & $\begin{array}{l}\text { MOD } \\
\text { ERAT } \\
\text { E }\end{array}$ & \begin{tabular}{|l} 
SEVE \\
RE
\end{tabular} & & & $\begin{array}{l}\text { Signi } \\
\text { fican } \\
\text { ce }\end{array}$ \\
\hline
\end{tabular}

\begin{tabular}{|c|c|c|c|c|c|c|c|}
\hline \multirow{3}{*}{$\begin{array}{l}\text { Severe } \\
\text { Disease - } \\
\text { RANSON } \\
\text { SCORE }\end{array}$} & MILD & $\begin{array}{l}22 \\
(64 . \\
71)\end{array}$ & $\begin{array}{l}10 \\
(58.82)\end{array}$ & $\begin{array}{l}7 \\
(13.73\end{array}$ & $\begin{array}{l}39 \\
(38 . \\
24)\end{array}$ & $<0.001$ & \multirow[t]{4}{*}{$\begin{array}{l}\text { Signi } \\
\text { fican } \\
\mathrm{t}\end{array}$} \\
\hline & MODERATE & $\begin{array}{l}10 \\
(29 . \\
41)\end{array}$ & $\begin{array}{l}4 \\
(23.53)\end{array}$ & $\begin{array}{l}22 \\
(43.14 \\
)\end{array}$ & $\begin{array}{l}36 \\
(35 . \\
29)\end{array}$ & & \\
\hline & SEVERE & \begin{tabular}{|l}
2 \\
$(5.8$ \\
$8)$
\end{tabular} & $\begin{array}{l}3 \\
(17.65)\end{array}$ & $\begin{array}{l}22 \\
(43.14 \\
)\end{array}$ & $\begin{array}{l}27 \\
(26 . \\
47)\end{array}$ & & \\
\hline Total & $34(100)$ & $\begin{array}{l}17 \\
(100 \\
)\end{array}$ & $\begin{array}{l}51 \\
(100)\end{array}$ & $\begin{array}{l}102 \\
(100)\end{array}$ & & & \\
\hline
\end{tabular}

Table 3: Determination Of Diagnostic Accuracy:

\begin{tabular}{|l|l|l|l|l|l|l|l|l|l|}
\hline $\begin{array}{l}\text { Scoring } \\
\text { system }\end{array}$ & TP & TN & FP & FN & $\begin{array}{l}\text { Sensi } \\
\text { tivity }\end{array}$ & $\begin{array}{l}\text { Speci } \\
\text { ficity }\end{array}$ & $\begin{array}{l}\text { Positive } \\
\text { Predicti } \\
\text { ve } \\
\text { Value }\end{array}$ & $\begin{array}{l}\text { Negat } \\
\text { ive } \\
\text { Prediagn } \\
\text { ctive } \\
\text { Value }\end{array}$ & $\begin{array}{l}\text { Diactic } \\
\text { accur } \\
\text { acy }\end{array}$ \\
\hline $\begin{array}{l}\text { Severe Disease } \\
\text { - CT Severity } \\
\text { Index Score }\end{array}$ & 22 & 46 & 29 & 5 & 81.48 & 61.33 & 43.14 & 90.20 & 66.67 \\
\hline $\begin{array}{l}\text { SEVERE } \\
\text { DISEASE - } \\
\text { GLASGOW } \\
\text { SCORE }\end{array}$ & 20 & 47 & 28 & 7 & 74.07 & 62.67 & 41.67 & 87.04 & 65.69 \\
\hline
\end{tabular}

All the results were obtained taking the Ranson's Prognostic criteria as the yardstick for comparison.

\section{CONCLUSION}

From this study, it may be concluded that Ranson's Prognostic Score, Glasgow Prognostic Score and the CT Severity Index correlate with each other in cases of Acute Pancreatitis. For mild cases of Acute Pancreatitis, CT scan may not be done if there is improvement in symptoms with conservative management. Glasgow Prognostic Scoring system and Ranson's Prognostic Score may be adequate to prognosticate the disease. When there is worsening of symptoms, or in cases of moderate to severe acute pancreatitis, when scoring systems like Ranson or Glasgow are used to prognosticate the disease, they must be supplemented by a CT scan, which is initially done after 72 hours of admission.

\section{CONFLICT OF INTEREST:}

The authors declare that there is no conflict of interest.

\section{REFERENCES}

1. Thomas E. Clancy, Stanley W. Ashley. Management of Acute Pancreatitis In: Michael J. Zinner, Stanley W. Ashley. Maingot's Abdominal Operations. Twelfth Edition. China: Cenveo Publisher Services; 2013. Pp. 1097.

2. Satyajit Bhattacharya. The Pancreas In: Norman S. Williams, Christopher J.K.Bulstrode, P. Ronan O' Connell. Bailey \& Love's Short Practice of Surgery. 26 Edition. Boca Raton: CRC Press; 2013. Pp. 1118.

3. Banks PA. Acute pancreatitis: medical and surgical management. Am J Gastroenterol.1994 Aug;89(8 suppl):S78-S85.

4. Beger HG, Rau B, Mayer J, Pralle U. Natural course of acute pancreatitis. World J Surg.1997 Feb;21(2):130-5.

5. Yousaf M, McCallion K, Diamond T. Management of severe acute pancreatitis. Br Surg. 2003 Apr;90(4):407-20.

6. Ranson JH, Rifkind KM, Roses DF, Fink SD, Eng K, Localio SA. Objective early identification of severe acute pancreatitis. Am J Gastroenterol. 1974;(61):443-51

7. Larvin M, McMahon MJ. APACHE-II score for assessment and monitoring of acute pancreatitis.Lancet.1989;(2):201-5.

8. Balthazar EJ, Robinson DL, Megibow AJ, Ranson JH. Acute pancreatitis: value of CT in establishing prognosis. Radiology. 1990;(174):331-6.

9. Koo BC, Chinogureyi A, Shaw AS. Imaging acute pancreatitis. Br J Radiol. $2010 \mathrm{Feb}$ 83(986): 104-12

10. William E. Fisher, Dana K. Andersen, John A. Windsor, Ashok K. Saluja, F. Charles Brunicardi. Pancreas. In: F. Charles Brunicardi, Dana K. Andersen, Timothy R. Billiar, David L. Dunn, John G. Hunter, Jeffrey B. Matthews et al. Schwartz's Principles of Surgery. Tenth edition. United States of America: Cenveo Publisher Services; Surgery. Ten

11. Satyajit Bhattacharya. The Pancreas In: Norman S. Williams, Christopher J.K.Bulstrode, P. Ronan O' Connell. Bailey \& Love's Short Practice of Surgery. 26 Edition. Boca Raton: CRC Press; 2013. Pp.1129.

12. Raghuwanshi S, Gupta R, Vyas MM, Sharma R. CT Evaluation of Acute Pancreatitis an its Prognostic Correlation with CT Severity Index. Journal of Clinical and Diagnostic Research : JCDR. 2016;10(6):TC06-TC11. doi:10.7860/JCDR/2016/19849.7934.

13. Fleszler F, Friedenberg F, Krevsky B, Friedel D, Braitman LE. Abdominal computed tomography prolongs length of stay and is frequently unnecessary in the evaluation of acute pancreatitis. Am J Med Sci. 2003:325:251-5.

14. King NKK, Powell JJ, Redhead D, Siriwardena AK. A Simplified Method for Computed Tomographic Estimation of Prognosis in Acute Pancreatitis. Scandinavian Journal O Gastroenterology.2003;38(4):433-6. 